\title{
The Special Issue in the Special Time
}

\author{
Jae Yeol Kim, M.D.
}

Department of Internal Medicine, Chung-Ang University College of Medicine, Seoul, Republic of Korea

The terror of coronavirus disease 2019 (COVID-19) pandemic is sweeping across the world. As of today (December 8, 2020), global cases of COVID-19 reached 67,591,203 with $1,544,533$ victims ${ }^{1}$. Korea is dealing with this dreadful contagion relative well and the cumulative cases of COVID-19 is 38,755 with 552 deaths as of today ${ }^{2}$. However, Korea is also experiencing the third wave of COVID-19 peak since middle of November. The problem is that we are entering the winter season. There are gloomy predictions that mass migration and reunion of family members for the celebration of Christmas and the end of year would lead to the explosion of new cases of COVID-19 in the January of next year. ${ }^{3}$. More worrisome is the fact that winter is also the season of influenza in the Northern hemisphere. COVID-19 and influenza share similar symptomatology, making differential diagnosis very difficult. The protracted hospital admissions and a higher risk of mortality of COVID-19 could potentially make the forthcoming northern hemisphere influenza season a public health catastrophe ${ }^{4}$. We might experience an unexperienced, mixed pandemic by COVID-19 and influenza, so called double-demic. Dr. Anthony Fauci, director of the National Institute of Allergy and Infectious Diseases, said regarding influenza vaccination in the era of COVID pandemic that "Get the flu shot! So that you could at least blunt the effect of one of those two potential respiratory infections." The symptoms of COVID-19 vary widely from asymptomatic infection to severe sepsis. However, fatal cases of COVID-19 are almost exclusively caused by severe pneumonia and even non-critical pneumonia survivors of COVID-19 suffered significant impairment in diffusion capac-

\section{Address for correspondence: Jae Yeol Kim, M.D.}

Department of Internal Medicine, Chung-Ang University College of Medicine, 102 Heukseok-ro, Dongjak-gu, Seoul 06973, Republic of Korea Phone: 82-2-6299-1396, Fax: 82-2-825-7571

E-mail: jykimmd@cau.ac.kr

Received: Dec. 8, 2020

Revised: Dec. 8, 2020

Accepted: Dec. 9, 2020

Published online: Dec. 9, 2020

(9) It is identical to the Creative Commons Attribution Non-Commercial License (http://creativecommons.org/licenses/by-nc/4.0/). The Korean Academy of Tuberculosis and Respiratory Diseases. ity and quality of life after being discharged from hospital ${ }^{5}$.

In this context, it is well-timed that the special issue of Tuberculosis and Respiratory Diseases was published in December. The special issue contains an article regarding COVID-19, "Risk factors for mortality among hospitalized patients with COVID-19. An overview in Mexican population" ${ }^{\prime 6}$. Preexisting respiratory diseases, specifically COPD, and smoking were associated with grave outcomes in COVID-19 cases $^{7}$. Important opinions regarding major respiratory diseases such as tuberculosis, chronic obstructive pulmonary disease, ozone associated lung injury, and lung cancer, which are also major risk factors for COVID-19 were covered in review articles and original papers of this special issue. I hope this special publication would be helpful for understanding and dealing with COVID-19 pandemic that we are desperately going through.

\section{Conflicts of Interest}

No potential conflict of interest relevant to this article was reported.

\section{References}

1. COVID-19 Dashboard by the Center for Systems Science and Engineering (CSSE) at Johns Hopkins University (JHU) [Internet]. Baltimore: Johns Hopkins University and Medicine, Coronavirus Resource Center; 2020 [cited 2020 Dec 8]. Available from: https://coronavirus.jhu.edu/map.html.

2. Korea Disease Control and Prevention Agency. Daily and cumulative cases of COVID-19 [Internet]. Cheongju: Korea Disease Control and Prevention Agency; 2020 [cited 2020 Dec 8]. Available from: http://www.kdca.go.kr/board/board.es?mid= a30402000000\&bid=0030.

3. Wormser GP. Impact of COVID-19 on Christmas. Wien Klin Wochenschr 2020;132:699-700.

4. Hills T, Kearns N, Kearns C, Beasley R. Influenza control during the COVID-19 pandemic. Lancet 2020;396:1633-4.

5. van der Brugge S, Talman S, de Winter LJ, de Mol M, Hoefman E, van Etten RW, et al. Pulmonary function and healthrelated quality of life after COVID-19 pneumonia. Respir Med 2021;176:106272.

6. Cortes-Telles A, Lopez-Romero S, Mancilla-Ceballos R, Ortiz- 
Farias DL, Nunez-Caamal N, Figueroa-Hurtado E. Risk factors for mortality among hospitalized patients with COVID-19: an overview in Mexican population. Tuberc Respir Dis 2020;83 Supple 1:S46-54.
7. Sanchez-Ramirez DC, Mackey D. Underlying respiratory diseases, specifically COPD, and smoking are associated with severe COVID-19 outcomes: a systematic review and metaanalysis. Respir Med 2020;171:106096. 